\section{Poles apart}

\section{Pearce Williams}

Hidden Attraction: The Mystery and History of Magnetism. By Gerrit L. Verschuur. Oxford University Press: 1993. Pp. 256. \$25, £20.

GERRIT L. Verschuur is an astronomer who has been fascinated by magnetism since his childhood. The development of the science of magnetism serves him as a model for the evolution of modern science as a whole. The history of magnetism is here presented in a popular form intended to appeal to a wide audience.

There are three themes in Hidden Attraction. The first, and most detailed, is the history of theories of magnetism; the second, included in the first, is the use of this history as the definition of what all science is about; and the third is a discussion of the future of science together with a scheme of the structure of scientific investigations from primitive man to the modern world. These are all important matters and it is unfortunate that Verschuur is largely unsuccessful in achieving his goals. A brief critical account will make the reasons clear.

The view of the history of science presented here is one that was popular about 75 years ago when the history of science was written largely by retired scientists.
Science begins only when "someone challenged the old beliefs and began to confront nature directly, which meant through experiment. Herein lies the essence of the scientific endeavor." This definition permits the author to ignore or belittle the whole of Greek and mediaeval science by dismissing what was done then as superstition. The result is bizarre. The Scientific Revolution for Verschuur begins with William Gilbert's book on the magnet.

The achievement of Copernicus, which involved neither experiment nor the introduction of new measurements, is virtually ignored, as is Isaac Newton's creation of classical mechanics and mathematical astronomy. Copernicus and Newton receive only one reference in the index, whereas Gilbert has 12. This peculiar perspective leads to the neglect of mathematics as a tool of discovery and the ignoring of the origins of hypotheses in philosophy, religion or personal bias. Science, we are told, can arise only from close observation and experiments. Two generations of historians of science have shown that this is simply not so.

The author's narrative is filled with factual errors and careless mistakes. It is not true that Galileo actually proved that the Earth was not at the centre of the Solar System, that Oersted's discovery of electromagnetism was an accident, that Humphry Davy discovered 47 new elements by electrolysis or that Ampère "discovered

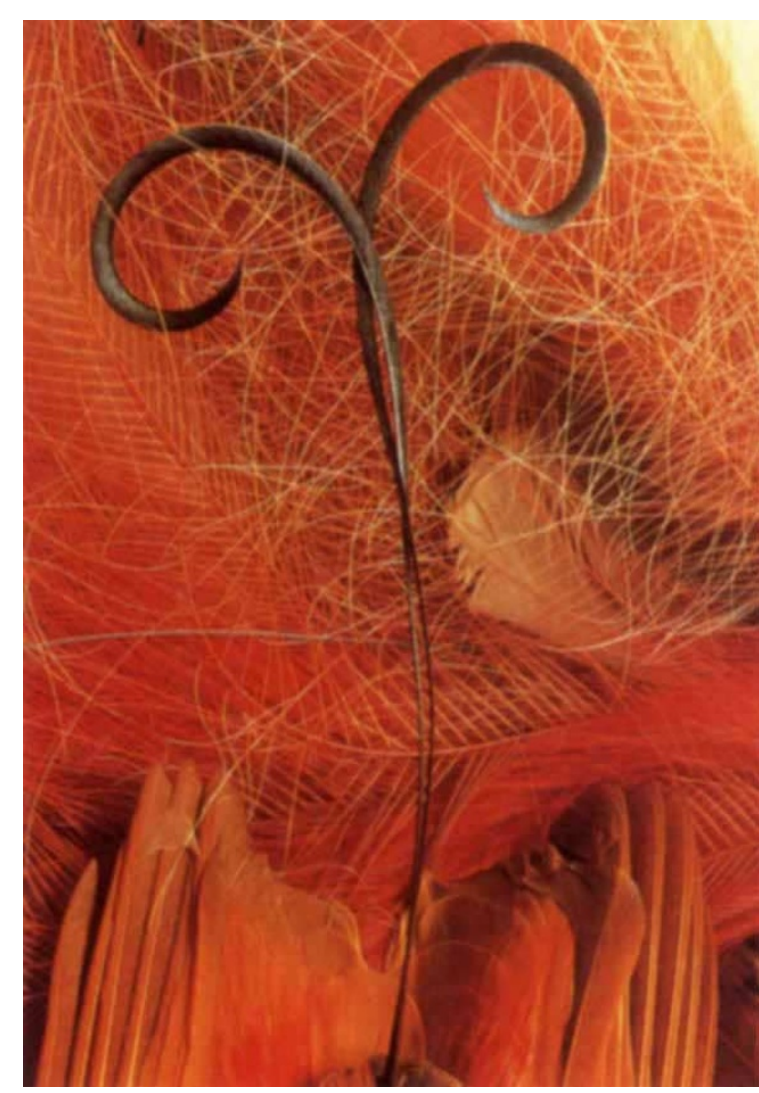

that a magnetic field is created by a current flowing through a wire" (the discovery is in fact properly attributed to Oersted earlier in the book). And so on.

Verschuur's scholarship is slipshod. References to works consulted, such as the Dictionary of Scientific Biography, on which he relies heavily, give neither authors' names nor the page numbers referred to. The citations are also untrustworthy. He cites, for example, without attribution, the five theories that Ampère was intent on proving and which are printed in an article in Faraday Rediscovered by D. Gooding and F. James (Macmillan, 1985). He changes the theories and, in doing so, misrepresents them. $\mathrm{He}$ does not even seem to understand them and one, in particular, makes no scientific sense. Ampère suggested that the central forces between elements of current in two current-carrying wires "are propagated by the vibrations of the luminiferous aether", but Verschuur writes that "the central forces were propagated through the air by vibrations of a luminiferous ether" (my italics), implying that no forces could be transmitted in a vacuum.

It is strange that in a work devoted to exact observations and measurements, no mention is to be found of the work of Gauss or Weber who, surely, completed what Gilbert had begun. The history of magnetism ends, essentially, with Heinrich Hertz and radio waves. The rest of the volume is devoted to a survey of magnetism in its many manifestations in the modern world and a coda that reflects the author's scientific credo.

This credo is reminiscent of Condorcet's famous Sketch of a Tableau of the Progress of the Human Mind in its optimism. Verschuur seems to be extremely naive in his conclusion that we shall soon know everything about everything in the Universe, which will then allow humanity fully to express its innate creativity. George Orwell's vision seems a more likely outcome.

In the final appendix, the author lays out a "Pattern of Progress" which, in a few short paragraphs and a one-page diagram, sums up, in his view, the way in which science progresses. He suspects that readers will find this simplistic; he is right.

I cannot end without directing some criticism to Oxford University Press. Reputable academic presses have traditionally followed the practice of sending out manuscripts for review by competent scholars in the field involved. Had they done so with this manuscript, the author would have been spared the embarrassment which its publication will inevitably produce.

L. Pearce Williams is in the Department of Science and Technology, Cornell University, 726 University Avenue, Ithaca. New York 14850, USA. 